\title{
Exercise induced compartment syndrome in a professional footballer
}

\author{
E Cetinus, M Uzel, E Bilgiç, A Karaoguz, M Herdem
}

Br J Sports Med 2004;38:227-229. doi: 10.1136/bjsm.2003.004630

Recurrent pain in the lower leg caused by exercise is a common problem in athletes. The main causes are exercise induced compartment syndrome, periostitis of the tibia, stress fracture, venous diseases, obliterative arterial diseases, and shin splints. Exercise induced compartment syndrome is the least common. A recurrent tightening or tense sensation and aching in anatomically defined compartments is pathognomonic. The symptoms are caused by abnormally high pressure in compartments of the leg during and after exercise. In this report, a case of exercise induced compartment syndrome in a professional footballer is described.

$\mathrm{R}$ ecurrent leg pain is a common problem in very active people. The main causes are exercise induced compartment syndrome (EICS), periostitis of the tibia, stress fractures, venous diseases, obliterative arterial diseases, and shin splints. ${ }^{1-4}$ EICS, which is also known as chronic exertional compartment syndrome and recurrent compartmental syndrome, can be misdiagnosed because it is relatively rare. It usually occurs in physically active people, especially runners. It was first described and successfully treated surgically by Mavor in 1956. ${ }^{5}$ Reneman described the clinical manifestations of exercise related chronic compartment syndrome and, in 1975, confirmed that the symptoms are caused by increased compartment pressure. ${ }^{6}$

This report describes a case of EICS, its treatment, and outcome in a professional footballer.

\section{CASE REPORT}

A 20 year old male professional footballer presented with a 18 month history of pain in the left lower leg brought on by running. The time before the onset of pain while running had decreased from 30 minutes to 10 minutes. The pain was described as a tightening over the posteromedial aspect of the lower leg. The symptoms could be relieved by rest. This condition had prevented the patient from playing football for the preceding six months. Initially he was treated by the team physiotherapist. As his symptoms had not resolved six months after the onset, he attended an orthopaedic outpatient clinic. Massage and oral anti-inflammatory drugs were tried without effect.

One year later, he was seen in our outpatient department. Physical examination of the left lower leg showed nothing remarkable at rest, but, immediately after exercise, considerable tenseness over the posteromedial aspect of the leg was observed. Passive dorsiflexion of the left foot caused pain in the calf. Plain radiography and magnetic resonance imaging of the left cruris produced no evidence of stress fracture or any soft tissue pathology. Doppler ultrasonography of the lower leg showed no evidence of either venous or obliterative arterial disease. EICS was suspected, and compartment pressure before and after exercise on a treadmill for
15 minutes was measured by Whitesides method ${ }^{7}$ (table 1). The diagnosis of left chronic posterior compartment syndrome brought on by exercise was subsequently established. Left posterior deep and superficial compartment fasciotomies were performed through a medial incision. Six weeks later the patient was allowed to run. Three months after the operation, he started playing football, without any limitations, in the second national league. At his last follow up eight months after the operation, he had no complaints.

\section{DISCUSSION}

The consequences of compartment syndrome are reduction in capillary blood perfusion for tissue viability and compromise of neuromuscular function as a result of high pressure within a closed fascial space. ${ }^{8}$ Compartment syndrome may be acute or chronic. Acute compartment syndrome has been well documented clinically. The most common causes are tibial fractures, muscle ruptures, crush injuries of the leg, and blood diseases. ${ }^{10-12}$

Chronic compartment syndrome has also been defined as an EICS or exertional compartment syndrome. The pathogenesis of EICS is not well known. However, muscle contraction can raise intracompartmental pressure. Muscle weight can increase by as much as $20 \%$ as a result of the increased tissue perfusion with exercise. This increase in muscle weight in return decreases the compartment volume if the surrounding fascial borders are unyielding and can lead to increased intracompartmental pressure. ${ }^{13-16}$ An increase in tissue pressure causes transudation of fluid into the interstitial space and disruption of the microcirculation. ${ }^{12} 1617$

Patient history is an important basis for the diagnosis of chronic compartment syndrome. Patients may complain of pain for months, even years, induced by exercise and relieved by rest. ${ }^{18}$ The pain is described as aching, tightening, cramping, sharp, or stabbing. Bilateral involvement has also been reported..$^{19}$ Schissel $^{2}$ reported on a patient with a one year history of pain in both lower legs brought on by running, biking, and extensive walking, resolving with rest. Detmer et $\mathrm{al}^{5}$ noticed the consistent clinical appearance of pain with exercise in 94 patients. Most (69) of these patients were runners whose athletic performances were adversely affected by the symptoms. Rest or cessation of exercise improved symptoms in $85 \%$ of 75 athletes. There was bilateral involvement in 82 patients, with a mean duration of symptoms of 22 months before the operation. Styf and Körner ${ }^{20}$ reported bilateral involvement in 11 of 19 patients with chronic anterior compartment syndrome. In our case, there was a history of 18 months of pain in the left lower leg before surgery.

On physical examination, there are few distinctive signs of EICS. Fascial defects may be found. ${ }^{12}$ There may be

Abbreviation: EICS, exercise induced compartment syndrome 
Table 1 Measurements of compartment pressure $(\mathrm{mm} \mathrm{Hg})$ in the left leg before and after exercise

\begin{tabular}{lllll}
\hline & $\begin{array}{l}\text { Deep } \\
\text { posterior }\end{array}$ & $\begin{array}{l}\text { Superficial } \\
\text { posterior }\end{array}$ & Anterior & Lateral \\
\hline Resting & 24 & 20 & 20 & 20 \\
1 min after exercise & 32 & 20 & 20 & 20 \\
15 min after exercise & 26 & 20 & 20 & 20 \\
\hline
\end{tabular}

sensory and motor findings due to nerve compression and ischaemia. ${ }^{120}$

Tendinitis, stress fracture, muscle strain, shin splints, and vascular disorders should be remembered on differential diagnosis of exercise induced lower leg pain. ${ }^{1-4}$ Measurement of intracompartmental pressure, bone scintigraphy, plain radiography, and computed tomography are important in establishing a definitive diagnosis. ${ }^{16}$ Styf $^{1}$ reported the diagnosis of chronic compartment syndrome in 26 of 98 patients referred for the condition and stressed the importance of intracompartmental pressure measurement, bone scintigraphy, plain radiography, nerve conduction velocity, and plethysmography in differential diagnosis. Logan et al ${ }^{13}$ and Martens et $a^{21}$ indicated that monitoring of intramuscular compartment pressure is the most specific investigation for confirming the diagnosis. There is no consensus on the best measurement technique; the methods suggested vary from the use of a Wick catheter to a slit catheter to a digital manometer..$^{2-4}{ }^{14}$ Intracompartmental pressure must be measured on resting, mid-exercise, and at specific times after exercise (5-15 minutes). Criteria for the diagnosis of EICS are: (a) appropriate clinical findings (development of pain and impaired muscle function during the exercise test); $(b)$ intracompartmental pressure exceeding $30 \mathrm{~mm} \mathrm{Hg}$ one minute after exercise; (c) return to normal values 5-10 minutes after exercise. ${ }^{14} 22$ Takebayashi et al ${ }^{23}$ have shown that thallium 201 SPECT imaging of the legs can give the precise location of the ischaemic compartment. This technique is promising for the screening and follow up of chronic EICS. ${ }^{23}$ In our patient, plain radiography and magnetic resonance imaging of the left cruris showed nothing of note and gave no evidence of bone or soft tissue pathology. Doppler ultrasonography of the lower leg provided no evidence of venous or obliterative arterial disease. From measurements of compartment pressure by Whitesides method, we were able to establish the diagnosis of EICS.

Treatment of EICS by exercise, orthotics, non-steroidal anti-inflammatory drugs, and activity modification has usually been unsuccessful in allowing return to previous levels of activity. ${ }^{2124}$ In footballers and athletes who are prevented from pursuing their sport by EICS, the treatment of choice is fasciotomy. ${ }^{19} 2025-27$

Massage, physiotherapy, and non-steroidal anti-inflammatory drugs had been tried in our case before the patient presented to our clinic. As he had not responded to these approaches, we performed a fasciotomy because a quick return to football was required.

Several techniques for fasciotomy have been describedfor example, fibulectomy, perifibular fasciotomy, double incision fasciotomy, endoscopically assisted fasciotomy, fasciotomy with a partial fasciectomy. ${ }^{5} 16222428$ All have been reported to yield good results. Moeyersoons and Martens ${ }^{18}$ reported that $84 \%$ of their results were excellent or good, and Styf and Körner ${ }^{20}$ reported that functional capacity was good in 18 of 19 patients and there were two recurrences. Rorabeck et $a l^{27}$ reported complete relief of symptoms in 10 of 12 patients. Detmer et al $l^{5}$ reported a recurrence rate of only $3.4 \%$. Fronek et $a l^{25}$ reported "no exertional pain after the fasciotomy" in 10 of 12 patients treated with subcutaneous fasciotomy. Slimmon et $a l^{28}$ reported excellent or good surgical outcome in $60 \%$ of their patients ( 37 of 62 ) after a fasciotomy with a partial fasciectomy, at a mean of 51 months follow up. Our patient was symptom free while playing football three months after the fasciotomy. Although fasciotomy is often successful in relieving pain, Mozan and Keagy $^{29}$ reported a $20 \%$ decrease in strength of the affected compartment. Detmer et $a l^{5}$ reported operative and postoperative complications including arterial injury requiring repair, haematoma/seroma, superficial wound infection, peripheral cutaneous nerve injury, lymphocele, and deep venous thrombosis. Slimmon et al ${ }^{28}$ reported some major complications arising from the operation: postoperative clotting in one patient, phlebitis in one patient, and a wound infection that lasted for 12 months in one patient. In $90 \%$ of their patients, minor postsurgical complications were reported: numbness, bruising and swelling, skin infections, increased sensitivity, and weakness. Fascial herniation, residual pain, or recurrence of the compartment syndrome because of inadequate release are other complications and causes of unsatisfactory results. ${ }^{22}$ In our patient, no complications occurred.

In conclusion, EICS should be considered in the differential diagnosis of lower leg pain in sportspeople. Professional footballers should not delay seeking medical attention. Initially they are usually treated by the team physiotherapist because orthopaedic surgeons and specialists in sports medicine are not routinely employed by professional football teams in Turkey (especially those in the second national league). After history taking and physical examination, diagnosis can be confirmed by measurement of intracompartmental pressure. In most cases, the definitive treatment of this condition is surgical fasciotomy. As in our patient, patients can usually return to full activity shortly after surgery.

\section{Authors' affiliations}

E Cetinus, M Uzel, E Bilgiç, A Karaoguz, Department of Orthopaedics, Faculty of Medicine, University of Kahramanmaras, Kahramanmaras, Turkey

M Herdem, Department of Orthopaedics, Faculty of Medicine, University of Çukurova, Adana, Turkey

Correspondence to: Dr Cetinus, Department of Orthopaedics, Faculty of Medicine, University of Kahramanmaras, 46050 Kahramanmaras,

Turkey; ercancetinus@hotmail.com

Accepted 31 March 2003

\section{REFERENCES}

1 Styf J. Diagnosis of exercise induced pain in the anterior aspect of the lower leg. Am J Sports Med 1988;16:165-9.

2 Schissel DJ. Effort related chronic compartment syndrome of the lower extremity. Mil Med 1999;164:830-2.

3 Wallensten R, Eriksson E. Intramuscular pressures in exercise induced lower leg pain. Int J Sports Med 1984:5:31-5.

4 Biedert RM, Marti B. Intracompartmental pressure before and after fasciotomy in runners with chronic deep posterior compartment syndrome. Int J Sports Med 1997; 18:381-6.

5 Detmer D, Sharpe K, Sufit R, et al. Chronic compartment syndrome: diagnosis, management and outcomes. Am J Sports Med 1985;13:162-70.

6 Reneman RS. The anterior and the lateral compartmental syndrome of the leg due to intensive use of muscles. Clin Orthop 1975;113:69-80.

7 Whitesides TE, Haney TC, Morimoto K, et al. Tissue pressure measurements as a determinant for the need of fasciotomy. Clin Orthop 1975;113:43-51.

8 Rorabeck C, Bourne R, Fowler P, et al. The role of tissue pressure measurement in diagnosing chronic anterior compartment syndrome. Am J Sports Med 1988;16:143-6.

9 Mubarak S, Hargens AR. Acute compartment syndromes. Surg Clin North Am 1983;63:539-65.

10 Hieb LD, Alexander AH. Bilateral anterior and lateral compartment syndromes in a patient with sickle cell trait:case report and review of the literature. Clin Orthop 1998;228:190-3. 
11 Mubarak S, Owen C, Hargens A, et al. Acute compartment syndromes: diagnosis and treatment with the aid of the Wick catheter. J Bone Joint Surg [Am] 1978;60:1091-5.

12 Straehley D, Jones WW. Acute compartment syndrome (anterior, posterior and superficial lateral) following tear of the medial head of gastrocnemius muscle. Am J Sports Med 1986;14:96-9.

13 Logan J, Rorabeck C, Castle G. The measurement of dynamic compartment pressure during exercise. Am J Sports Med 1983;1 1:220-3.

14 Melberg P, Styf J. Posteromedial pain in lower leg. Am J Sports Med 1989;17:747-50.

15 McDermott A, Marble A, Yabsley R, et al. Monitoring dynamic anterior compartment pressures during exercise. Am J Sports Med 1982;10:83-9.

16 Andrish JT. The leg. In: DeLee JC, Drez D Jr, eds. Orthopaedic sports medicine: principles and practise, 1st ed. Philadelphia: WB Saunders, 1996:1612-19.

17 Detmer D. Chronic leg pain. Am J Sports Med 1980;8:141-4.

18 Moeyersoons JP, Martens M. Chronic compartment syndrome: diagnosis and management. Acta Orthop Belg 1992;58:23-7.

19 Martens MA, Moeyersoons JP. Acute and recurrent effort related compartment syndromes in sports. J Sports Med 1990:62-8.

20 Styf J, Körner L. Chronic anterior compartment syndrome of the lower leg: results of treatment by fasciotomy. J Bone Joint Surg [Am] 1986;69:1338-47.

21 Martens MA, Backaert M, Vermault $G$, et al. Chronic leg pain in athletes due to recurrent compartment syndrome. Am J Sports Med 1984;12:148-51.
22 Clanton TO. Athletic injuries to the soft tissues of the foot and ankle. In: Coughlin MJ, Mann RA, eds. Surgery of the foot and ankle, 7th ed. St Louis: Mosby, 1999:1101-6.

23 Takebayashi S, Takazawa H, Sasaki R, et al. Chronic exertional compartment syndrome in lower legs: localization and follow-up with thallium-201 SPECT imaging. J Nucl Med 1997;38:972-6.

24 Leversedge FJ, Casey PJ, Seiler III SG, et al. Endoscopically assisted fasciotomy: description of technique and in vitro assessment of lower leg compartment decompression. Am J Sports Med 2002;30:272-8.

25 Fronek J, Mubarak S, Hargens A, et al. Management of chronic exertional anterior compartment syndrome of the lower extremity. Clin Orthop 1987;220:217-27

26 Rorabeck C, Fowler P, Nott L. The results of fasciotomy in the management of chronic exertional compartment syndrome. Am J Sports Med 1988;16:224-7.

27 Rorabeck CH, Bourne RB, Fowler PJ. The surgical treatment of exertional compartment syndrome in athletes. J Bone Joint Surg [Am] 1983;65:1245-51.

28 Slimmon D, Bennell K, Brukner $P$, et al. Long term outcome of fasciotomy with partial fasciectomy for chronic exertional compartment syndrome of the lower leg. Am J Sports Med 2002;30:581-8.

29 Mozan LC, Keagy RD. Muscle relationship in function fascia. Clin Orthop $1969 ; 67: 225-30$ 